\title{
MJMR AWARENESS OF MOTHER'S REGARDING UNDER FIVE DANGER SIGNS IN A SELECTED RURAL COMMUNITY OF WEST BENGAL
}

\author{
Baisakhi Sarkar \\ ${ }^{I}$ Clinical Instructor, Govt College of Nursing, NRS Medical College and Hospital, Kolkata, West Bengal, India \\ Corresponding Author’s Email: rumibaisakhi2009@gmail.com
}

\begin{abstract}
Background: The first five years constitute the foundations of the child's physical, mental growth and development. Mortality and morbidity are higher among this age group. Early detection of danger signs are very crucial to prevent such. The objectives were to assess the knowledge of mothers regarding under-five danger signs \& explore the association and causal effect between such knowledge with selected factors. Methodology: A descriptive study was conducted in a rural community of West Bengal from Jan'2018 to Sept'2018. Total study sample was 110 mothers having under five children. Door to door data collection was done by using interview technique $\&$ data has been analyzed by both manually and computer feeding. Results: Out of total study sample, majority (60\%) belongs to age group $18-25$ years followed by $31 \%$ among 26-33 age group, then $16 \%$ were more than 33 years. Out of total mothers majority ( $40 \%$ ) belongs to higher educated group, $(37 \%)$ secondary group, followed by $(10 \%)$ has primary education and $(13 \%)$ were illiterate. Knowledge score was more than 50\% among higher educated group (64\%). Out of total respondents $61(55.5 \%)$ mother's were not able to identify any danger signs whereas $(35.5 \%)$ mothers identified 1-2 danger signs and (9\%) mothers able to identify 3-4 danger signs. Knowledge score about danger signs was more who visited antenatal clinic more than 4 times(61\%). Conclusions: Awareness regarding under five danger signs are more among higher educated mothers. Number of antenatal visits also influence knowledge score.
\end{abstract}

\section{Keywords : Awareness, Under-five, Danger signs, Mothers}

\section{INTRODUCTION}

The first five years constitute the foundations of the child's physical, mental growth and development. The child needs regular health supervision throughout infancy and for several years afterwards. UNICEF also considers under five mortality rate is the best single indicator of social development \& well-being rather than GNP per capita, as the former reflects income, nutrition, health care \& basic education etc. In 2015, about half of the global under-five deaths occurred in sub-Saharan Africa \& $32 \%$ in South Asia. Almost 40\% of under-five death occurred in 2015 is due to infectious diseases \& conditions such as pneumonia, diarrhea, malaria, meningitis, tetanus, HIV \& measles. Mentioned diseases are all most all preventable and considered as danger signs. Around $45 \%$ of all underfive deaths occurred in the neonatal period. Globally, more than half of the under-five deaths are attributable to under-nutrition (Park, 2017).

Pneumonia, diarrhoea and malaria remain the leading causes of death among children under-five years of age accounting for about 30 per cent of global under-five deaths. The leading causes of death among children under-five in 2016 included preterm birth complications (18\%), pneumonia (16\%), intrapartumrelated events $(12 \%)$, congenital abnormalities $(9 \%)$, diarrhoea ( $8 \%$ ), neonatal sepsis $(7 \%)$ and malaria $(5 \%)$ (Unicef, 2019). Worldwide Acute Ottitis Media affects about $11 \%$ of people a year (about 325 to 710 million cases) among them half the cases are children less than five years of age. Evidence suggest that severe cases of ear infection leads to impaired hearing which will affect learning, behavioural and social attitude and speaking capacity-indirectly in society.

Danger signs refers the presence of clinical signs that would indicate high risk of their morbidity \& mortality and need early therapeutic intervention include fever, pneumonia, diarrhea, malnutrition, anaemia, ear problem etc. Any delay in identification of it or initiation of treatment of danger signs means the child is more likely to die from the illness. In neonatal period early detection of neonatal danger signs is important to improve new born survival and it is also important for 
the mothers to be able to identify signs in neonates that signifies severe neonatal illnesses. A newborn can die within minutes if prompt recognition, diagnosis and treatment are not initiated. So at home if proper identification of danger signs not done then health facility related delays can contribute to subsequent delays of treatment initiation and newborn deaths. These delays especially at the household level are particularly important because once there is a delay in the recognition of the danger signs of newborn illnesses are automatically delays at all other levels i.e. initiation of appropriate treatment and/or referral to a better resourced hospital. Therefore, it becomes necessary to make the mothers aware regarding under-five danger signs(Awasthi \& Agarwal, 2006).

Each year about 27 million children are born in India \& $10 \%$ of them do not survive to 5 years of age. India alone contributes $25 \%$ of deaths in under- 5 children occurring worldwide every year. A study was done to know the modifiable causes of under 5 child mortality at Chandigarh on 2012. Among other causes inability to recognize danger signs is one of them (Mahajan, Kaur, Sharma, Azad \& Guglani 2014; Waiswa, Kallander, Peterson, Tomson \& Pariyo 2010; Choi, El, Mannan, Rahman, Bari et al. 2010).

The present study was therefore designed to assess the knowledge of mothers regarding under- five danger signs in rural community of West Bengal and to explore association between such knowledge with selected socio-demographic factors. I envisioned that such assessment will help to design and intervene a need based education program to make mother's aware regarding under- five danger signs.

\section{METHODOLOGY}

A descriptive study was conducted from January 2018September 2018 among mothers who have under-five children. Field practice area of Rural training center of NRS Medical College under Hariharpur Block Primary Health Centre(BPHC) was study area. An extensive field survey along with sample selection, post collection data analysis was carried out. In this study mother's of three (3) Sub-centers was interviewed. Out of total 247 mothers 110 were randomly selected from a list obtained from ASHA(Accredited Social Health Activist) and maintained by SC separately. Mothers who have more than one under-five children information of younger child was collected. The
Institutional Ethical Committee approved the study Consenting mothers were interviewed using a structured questionnaire for knowledge and semi-structured questionnaire for general information. Semi-structured questionnaire includes 21 items to collect demographic details like religion, type of family, parity, types of health care services available etc. Structured questionnaire consists 22 knowledge questionnaires on under five danger signs. Among them one(1) has binary response and 1(one) question may get multiple responses. Other 20 (tweenty) items has 3 alternatives. A score value of 1 (one) is allotted to each correct answer and 0 (zero) for incorrect answer. The total score is $0-20$ (zero-twenty)

The obtained data were coded, cleaned, recoded and calculated manually and by using data analysis tool pack in excel. Simple descriptive statistics like charts, tables is used in analyzing the frequency and percentage distribution, mean \& SD. Association of knowledge score with selected demographic factors analyzed by frequency and percentage distribution \& Chi-square test of association.

\section{RESULTS}

Socio demographic characteristics of respondents: Before starting any kind of data analysis given the study objectives, it is prior to provide a glimpse of socio economic conditions of the sample households. Table1 shows the socio demographic characteristics mainly in a compact way.

Out of total respondent $63.63 \%$ mother were Hindu by religion whereas $36.36 \%$ are Muslim . Type of family is almost same for all three category nuclear, joint \& extended. Most of (57\%) the mother's age in between $18-25$ years, $15 \%$ belongs to $26-33$ years age group, $14.54 \%$ mothers age is above 33 years and $2.72 \%$ are below 18 years. Maximum (79\%) mothers have one under five children and $21 \%$ mothers have above one under five children. Most of the (53\%) mothers have parity one and $47 \%$ have above one parity(Table 1) .

Table: 1 Showing demographic characteristics of respondents, $n=110$

\begin{tabular}{|l|l|l|}
\hline Variables & Frequency & Percent (\%) \\
\hline Religion & & \\
Hindu & 70 & 63.63 \\
Muslim & 40 & 36.36 \\
\hline
\end{tabular}




\begin{tabular}{|c|c|c|}
\hline \multicolumn{3}{|l|}{ Caste } \\
\hline General & 77 & 70 \\
\hline Schedule caste & 33 & 30 \\
\hline \multicolumn{3}{|l|}{ Type of family } \\
\hline Nuclear - & 36 & 32.7272 \\
\hline Joint - & 39 & 35.45 \\
\hline Extended - & 35 & 31.1818 \\
\hline \multicolumn{3}{|c|}{ No. of under five children } \\
\hline 1 & 87 & 79 \\
\hline 2 & 23 & 21 \\
\hline \multicolumn{3}{|c|}{ Present age of mother } \\
\hline$<18$ & 3 & 2.72 \\
\hline$\geq 18-25$ & 60 & 54.54 \\
\hline $26-33$ & 31 & 28.1818 \\
\hline$>33$ & 16 & 14.54 \\
\hline \multicolumn{3}{|l|}{ Pariety } \\
\hline 1 & 58 & 53 \\
\hline$\geq 2$ & 52 & 47 \\
\hline
\end{tabular}

Table 1 showing out of total respondent, $63.63 \%$ mother were Hindu by religion whereas $36.36 \%$ are Muslim . Type of family is almost same for all three category nuclear, joint \& extended. Most of (57\%) the mother's age in between $18-25$ years, $15 \%$ belongs to 26-33 years age group, $14.54 \%$ mothers age is above 33 years and $2.72 \%$ are below 18 years . Maximum (79\%) mothers have one under five children and $21 \%$ mothers have above one under five children. Most of the $(53 \%)$ mothers have parity one and $47 \%$ have above one parity

We know that in this study educational attainment is an important factor that can induce a mothers knowledge about danger signs. Hence the Figure 1 is exhibiting the distribution of educational attainment of the mothers of sample households. According to the figure it was found that $40 \%$ mothers passed higher secondary $\&$ above followed by $37 \%$ secondary, $10 \%$ primary and $13 \%$ were illiterate (Figure 1).

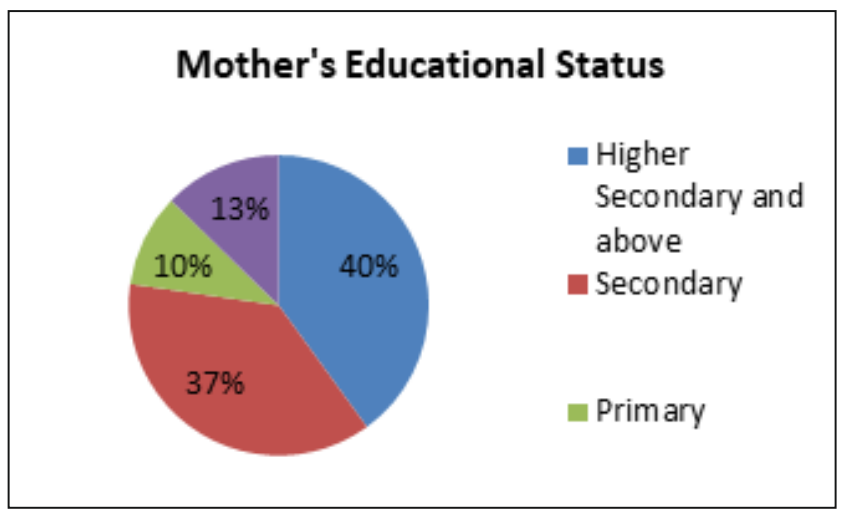

Figure 1: Showing educational status of respondents, $n=110$

Among all mothers $40 \%$ mothers passed higher secondary \& above followed by $37 \%$ secondary, $10 \%$ primary and $13 \%$ were illiterate.

Occupational status of the mothers and per capita income across sample households is another two major economic characteristics as it implies a kind of economic freedom and empowerment. Study reveals out of 110 mothers 79 were housewives, 15 mothers were engaged in labor work, 9 mothers had either Govt or private job, 5 mothers were self-employed and 2 are business women (Figure 2).

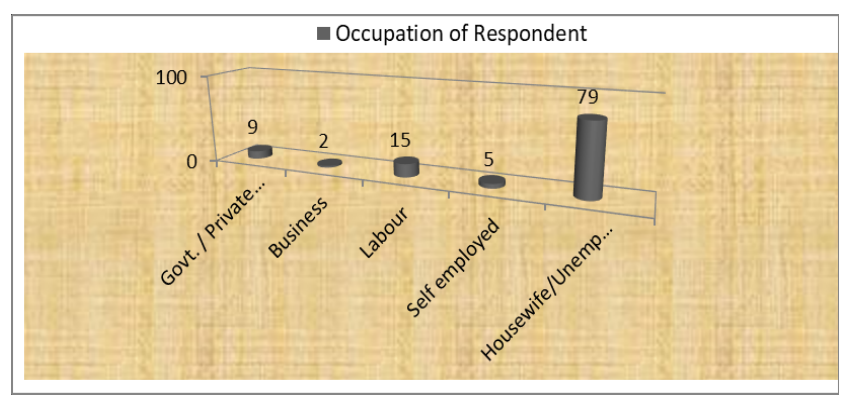

Figure 2: Showing occupational status of respondents, $n=110$

Study reveals out of 110 mothers 79 were housewives, 15 mothers were engaged in labor work, 9 mothers had either Govt or private job, 5 mothers were selfemployed and 2 are business women

Out of all, $40 \%$ mothers belongs to Social Class IV, followed by $30 \%$ in Social Class III and $21.81 \%$ in II and only $8.18 \%$ fall in Social Class I(Table 2). Social Class were decided as per Modified B.G.Prasad Scale(2018). 
Table -2 Showing distribution of per capita income of respondents, $n=110$

\begin{tabular}{|l|c|c|}
\hline Social Class*(Rs / Month) & No & Percent (\%) \\
\hline I( $\geq$ Rs 6574/-) & 9 & 8.18 \\
II (Rs. 3287- 6573/ -) & 24 & 21.81 \\
III( Rs. 1972 - 3286 /-) & 33 & 30 \\
IV (Rs. 986- 1971/-) & 44 & 40 \\
V ( Rs. $\leq 985)$ & 00 & 00 \\
\hline
\end{tabular}

*Social Classes were decided as per Modified B.G.Prasad Scale 2018

Table 2 depicts out of all $40 \%$ mothers belongs to Social Class IV, followed by $30 \%$ in Social Class III and $21.81 \%$ in II and only $8.18 \%$ fall in Social Class I

Uses of Health Care Services: Proper utilization of health care facilities has a crucial role in maintaining health for all. In this study above 50\% mothers visits Antenatal clinic less than 4 times in compare to $49 \%$ who visits more than 4 times. Most of the mothers(44.54\%) didn't visit post natal clinic and $42.72 \%$ mothers visits post natal clinic only $1-2$ times(Table 3).

Table 3 - Shows Frequency and percentage distribution of utilization of health care services by respondents, $n=110$

\begin{tabular}{|l|c|c|}
\hline Variables & Frequency & Percent (\%) \\
\hline ANC & & \\
$<4$ times & 56 & 50.90 \\
$\geq 4$ times & 54 & 49 \\
\hline PNC & & \\
Not done & 49 & 44.54 \\
1 -2 times & 47 & 42.72 \\
3-4 times & 14 & 12.72 \\
\hline
\end{tabular}

Above table shows above 50\% mothers visits Antenatal clinic less than 4 times in compare of $49 \%$ who visits more than 4 times. Most of the mothers (44.54\%) didn't visit post natal clinic and $42.72 \%$ mothers visits post natal clinic only 1-2 times

Data represented in Table 4 showed that majority (75 $\%$ of subjects have preferred institutional delivery. (Table 4) Delivered at Frequency Percent
Table 4: Showing frequency and percentage distribution of respondents in terms of preferences of places for child birth, $n=110$

\begin{tabular}{|l|c|c|}
\hline Delivered at & Frequency & Percent (\%) \\
\hline Hospital & 82 & 74.5454 \\
\hline Home & 11 & 10 \\
\hline Nursing home & 17 & 15.45 \\
\hline
\end{tabular}

Awareness on under-five danger signs: Danger signs are those which needs urgent care to decrease mortality and morbidity among under-five. Out of total 110 respondent $49(44.54 \%)$ heard about danger signs. Among all danger signs mothers are more aware about dehydration followed by convulsion and breathing difficulty. None of the mother is aware of anaemia and ear problem as danger signs for underfive children(Table 5).

Data represented in Table 5 showed that majority $(75 \%)$ of subjects have preferred institutional delivery

Table 5: Showing distribution of mothers by their knowledge about danger signs. $n=110$

\begin{tabular}{|c|c|c|c|}
\hline Variables & Response & Frequency & $\begin{array}{c}\text { Percent } \\
(\%)\end{array}$ \\
\hline \multirow{2}{*}{$\begin{array}{l}\text { Heard about } \\
\text { danger signs }\end{array}$} & Yes & 49 & 44.54 \\
\hline & No & 61 & 55.45 \\
\hline \multirow{10}{*}{$\begin{array}{l}\text { List of } \\
\text { danger signs }\end{array}$} & Lethargy & 8 & 7.27 \\
\hline & Poor feeding & 6 & 5.45 \\
\hline & Breathing difficulty & 55 & 50 \\
\hline & Fever & 19 & 17.27 \\
\hline & $\begin{array}{l}\text { Coldness of body (only } \\
\text { for } 0-2 \text { months ) }\end{array}$ & 7 & 6.36 \\
\hline & Convulsion & 57 & 51.81 \\
\hline & Severe Dehydration & 63 & 57.27 \\
\hline & Malnutrition (only for $2 \mathrm{~m}-5 \mathrm{yrs}$ ) & 19 & 17.27 \\
\hline & Anaemia(only for $2 \mathrm{~m}-5 \mathrm{yrs}$ ) & 0 & 0 \\
\hline & Ear problem(only for $2 \mathrm{~m}-5 \mathrm{yrs}$ ) & 0 & 0 \\
\hline
\end{tabular}

Out of total 110 respondent 49(44.54\%) heard about danger signs. Among all danger signs mothers are more aware about dehydration followed by convulsion and breathing difficulty. None of the mother is aware of anaemia and ear problem 
Mean knowledge score of mothers is 6.79 and SD is 2.552(Table 6).

Table -6 - Shows Mean Knowledge score \& SD of respondents, $n=110$

\begin{tabular}{|l|l|l|l|}
\hline Group & Test & Mean & SD \\
\hline Mothers & Baseline data & 6.79 & 2.552 \\
\hline
\end{tabular}

Table 7 depicts that $61(55.45 \%)$ mother's out of 110 not able to identify any danger signs whereas 39 $(35.45 \%)$ mothers identified $1-2$ danger signs and 10 $(9.09 \%)$ mothers able to identified 3-4 under five danger signs.

Table -7: Showing number of identified danger signs by respondents, $n=110$

\begin{tabular}{|l|c|c|c|}
\hline Variables & Response & Frequency & Percent (\%) \\
\hline No of enlisted & None & 61 & 55.45 \\
danger signs & $1-2$ & 39 & 35.45 \\
identified & $3-4$ & 10 & 9.09 \\
& $>5$ & 00 & 00 \\
\hline
\end{tabular}

This table depicts that $61(55.45 \%)$ mother's out of 110 not able to identify any danger signs whereas 39 $(35.45 \%)$ mothers identified 1-2 danger signs and 10 $(9.09 \%)$ mothers able to identified 3-4 under five danger signs.

This study revealed that $90(81.81 \%)$ out of 110 mothers perceived cough \& cold as danger signs and $76(69.09 \%)$ out of 110 mothers think continuous crying is a danger sign for children. Out of 110, 37 thinks 'Not playful', 34 'Don't Laugh' is also danger signs for under-five(Figure 3).

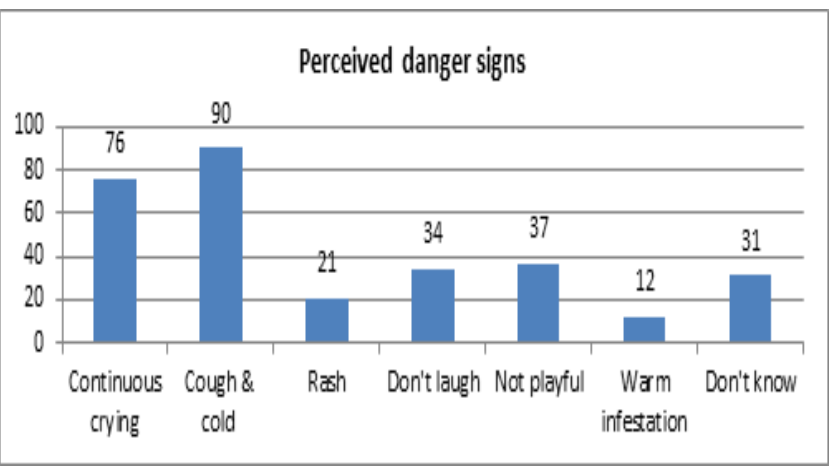

Figure 3 : Shows perceived danger signs identified by respondents, $n=110$

This figure shows $90(81.81 \%)$ out of 110 mothers perceived cough \& cold as danger signs and $76(69.09 \%)$ out of 110 mothers think continuous crying is a danger sign for children. Out of 110, 37 thinks 'Not playful', 34 'Don't Laugh' is also danger signs for under-five.

As I discussed earlier that higher education among mothers, regular antenatal and post natal visits to health facilities can increase knowledge on under-five danger signs. This study revealed that $64 \%$ mothers scored $>50$ who has more educational qualification than who are less qualified and more antenatal and post natal visits to health facilities has a influence on knowledge score.(Table 8,9).

Table 8: Showing association of Socio-economic characteristics with knowledge score of respondents, $n=110$

\begin{tabular}{|c|c|c|c|c|c|c|}
\hline \multirow[t]{2}{*}{ Variables } & \multirow{2}{*}{$\begin{array}{c}\text { Total Frequency } \\
(\%)\end{array}$} & \multicolumn{2}{|c|}{ Knowledge score } & \multirow[t]{2}{*}{ Chi square } & \multirow[t]{2}{*}{ df } & \multirow[t]{2}{*}{$P$ value } \\
\hline & & $<50(\%)$ & $\geq 50(\%)$ & & & \\
\hline \multicolumn{7}{|l|}{ Mother's } \\
\hline $\begin{array}{l}\text { Higher Secondary } \\
\text { and above }\end{array}$ & $44(40)$ & $16(36)$ & $28(64)$ & \multirow[t]{4}{*}{9.1387} & \multirow[t]{4}{*}{3} & \multirow[t]{4}{*}{$0.027502^{*}$} \\
\hline Secondary & $41(37)$ & $23(56)$ & $18(44)$ & & & \\
\hline Primary & $11(10)$ & $7(64)$ & $4(36)$ & & & \\
\hline $\begin{array}{l}\text { No formal } \\
\text { education }\end{array}$ & $14(13)$ & 11(79) & $3(21)$ & & & \\
\hline \multicolumn{7}{|l|}{$\begin{array}{l}\text { Mother's } \\
\text { occupation }\end{array}$} \\
\hline Housewives & $79(72)$ & $52(66)$ & $27(34)$ & 0.7191 & 1 & 0.396443 \\
\hline Others & $31(28)$ & $23(74)$ & $8(26)$ & & & \\
\hline \multicolumn{7}{|l|}{$\begin{array}{l}\text { Per capitaincome/ } \\
\text { month(Rs.) }\end{array}$} \\
\hline $\mathrm{I}(\geq$ Rs. $6574 /-)$ & $9(8.18)$ & $3(33.3)$ & $6(66.7)$ & 6.072 .9 & 3 & 0.108116 \\
\hline II (Rs.3287-6573/-) & $24(21.81)$ & $13(54.2)$ & $11(45.8)$ & & & \\
\hline III(Rs.1972-3286/-) & $33(30)$ & $24(72.7)$ & $9(27.3)$ & & & \\
\hline IV (Rs.986-1971/-) & $44(40)$ & $30(68.2)$ & $14(31.8)$ & & & \\
\hline V ( Rs. $\leq 985)$ & 00 & & & & & \\
\hline
\end{tabular}

Study reveals $64 \%$ mothers scored $>50$ has more educational qualification than who has less qualified. That means education has influence on knowledge score 
Table 9: Shows association of utilization of health care services and knowledge score by respondents, $n=110$

\begin{tabular}{|c|c|c|c|c|c|c|}
\hline \multirow[t]{2}{*}{ Variables } & \multirow{2}{*}{$\begin{array}{c}\text { Total } \\
\text { Frequency } \\
(\%)\end{array}$} & \multicolumn{2}{|c|}{ Knowledge score } & \multirow[t]{2}{*}{ Chi square } & \multirow[t]{2}{*}{ df } & \multirow[t]{2}{*}{$p$-value } \\
\hline & & $<50(\%)$ & $\geq(50 \%)$ & & & \\
\hline ANC Visit done & & & & & & \\
\hline$<4$ & $56(50.90)$ & $42(75)$ & $14(25)$ & 14.6493. & 1 & $0.000129 *$ \\
\hline$\geq 4$ & $54(49.09)$ & 21(38.9) & $33(61.1)$ & & & \\
\hline PNC Visit done & & & & & & \\
\hline Not Done & $49(45)$ & $43(88)$ & $6(12)$ & 17.2892 & 2 & $0.000176^{*}$ \\
\hline 1-2 Times & $47(43)$ & $28(60)$ & $19(40)$ & & & \\
\hline 3-4 Times & $14(13)$ & $5(36)$ & $9(64)$ & & & \\
\hline
\end{tabular}

Study findings shows more antenatal and post natal visits to health institution has a significant effect of knowledge on under five danger signs.

This project would never been possible without the support and guidance of various people of The West Bengal University Of Health Sciences. The author is thankful to Prof. Dr. A. Haldar,Principal, ID \& BG Hospital, Kolkata \& Prof. Dr. N.K.Mondal, HOD, Community Medicine, Malda Medical College \& Hospital for giving me the opportunity to continue my research under their supervision, it is truly an honour. Thank you for all the advice, ideas, moral support and patience in guiding me through this project. I would like to thank 24 Parganas (South) District Health Office and Block Health Office, ANM \& ASHA for their co-operation in getting necessary information. I'm extremely grateful to mother's who participated in the study to share their experiences.

\section{DISCUSSION}

This study showed that mothers who are higher educated is more aware and who has visited ante natal clinic or post natal clinic are more aware than others. In one study mothers were identified as the danger signs of childhood illness are fever (51\%), child becoming sicker $(45.2 \%)$ and drinking poorly $(42.5 \%)$ at Nepal (Sreeramareddy, Shankar, Sreekumaran, Subba, Joshi \& Ramachandran 2006). This study reveals $81.81 \%$ mothers perception about danger sign is cough \& cold followed by (69.09\%)continuous crying , (36.63\%)'Not playful' \& (30.90\%) 'Don't Laugh'. Awareness about danger signs among mothers is very poor which is very crucial (Baqui, Arifeen, Rosen, Mannan, Rahman, Billah, Al-Mahmud et al. 2009).

The small size might have limited our ability to find association with other variables.

\section{CONCLUSION}

Various studies shows if mothers are aware of under-five danger signs then they could take early initiation to seek proper treatment and help reduction in child morbidity and mortality. This study revealed that literacy status, antenatal and post natal visits to health facilities have great influence about knowledge on under-five danger signs. Despite the fact that global neonatal mortality rate has declined significantly still it needs urgent attention on prevention. There is therefore urgent need to incorporate and/or consolidate the teaching to expectant mothers during ANC on these danger signs on repeated basis.

\section{REFERRENCES}

Awasthi, S. V. T., Agarwal, M., (2006) Danger signs of neonatal illnesses: perceptions of caregivers and health workers in northern India. Bulletin of the World Health Organization, 84,

Baqui A H, Arifeen S E, Rosen HE, Mannan I, Rahman, Billah A, Al-Mahmud et al.(December 2009) Tropical Medicine \& International Health, 14(12) pp:1448-1456.

Choi, Y., El, Arifeen, S., Mannan, I., Rahman, S.M., Bari, S., Darmstadt, G.L., Black, R.E., Baqui, A.H.; Projahnmo Study Group. (2010) Can mothers recognize neonatal illness correctly? comparison of maternal report and assessment by community health workers in rural Bangladesh. Tropical Medicine \& International Health 15(6) pp: 743-753.

Mahajan V, Kaur A, Sharma A, Azad C and Guglani V.(2014) Indian Pediatric, 51, pp: 45-47. Retrieved from: http://www.indianpediatrics.net/jan2014/ jan-45-47.htm 
Park, K.(2017). Park's textbook of preventive \& social medicine: Preventive medicine in obstetrics, paediatrics \& geriatrics. (pp- 608 $\neg-614)$. Jabalpur, M.P: Banarsidas Bhanot.

Unicef (2019). Under-five Mortality. Retrieve from: https://data.unicef.org/topic/child-survival/underfive-mortality/

Sreeramareddy, C.T., Shankar, R.P., Sreekumaran, B.V., Subba, S.H., Joshi, H.S., Ramachandran, U.
(2006) Care seeking behaviour for childhood illness--a questionnaire survey in western Nepal. BMC International Health Human Rights. 23(6) pp:7.

Waiswa P, Kallander K, Peterson S, Tomson G, Pariyo, G.W. (2010) Using the three delays model to understand why newborn babies die in eastern Uganda. Tropical Medicine \& International Health 15(8) pp: 964-972. 